\title{
Metástase retroperitoneal, hepática e de linfonodo de osteossarcoma tibial proximal: Relato de caso*
}

\section{Retroperitoneal, Liver and Lymph Node Metastasis from Proximal Tibial Osteosarcoma: A Case Report}

\author{
${ }^{1}$ Department of Orthopedics and Traumatology, Pontificia \\ Universidad Javeriana, Bogotá, Colômbia \\ 2 Department of Orthopedics and Traumatology, Pontificia Universidad \\ Javeriana, Hospital Universitario San Ignacio, Bogotá, Colômbia \\ ${ }^{3}$ Department of Orthopedic Oncology, Pontificia Universidad \\ Javeriana, Hospital Universitario San Ignacio, Bogotá, Colômbia \\ 4 Department of Pathology, Pontificia Universidad Javeriana, Hospital \\ Universitario San Ignacio, Bogotá, Colômbia
}

Daniela Gutierrez $^{10}$ Carlos A. Sánchez ${ }^{20}$ Francisco B. Linares ${ }^{2,3(0)}$ Oscar Messa $4(0$

\begin{abstract}
Endereço para correspondência Carlos A. Sánchez, MD, Orthopedist and Traumatologist, Pontificia Universidad Javeriana, Hospital

Universitario San Ignacio, Bogotá, Colombia, Cra 7 \# 40-62, zip code: 110231, Bogotá, Colombia (e-mail: sanchez210590@gmail.com).
\end{abstract}

Rev Bras Ortop

\section{Resumo \\ Palavras-chave \\ - osteossarcoma \\ - tíbia \\ - metástase \\ - metástase linfática}

Homem adulto com osteossarcoma na tíbia proximal, tratado com cirurgia de salvamento de membro com endoprótese e quimioterapia. Ele desenvolveu um padrão metastático incomum, comprometendo fígado, ossos e linfonodos inguinais, sem recorrência local na tíbia nem metástases pulmonares. O osteossarcoma (OS) é o segundo tumor ósseo primário mais frequente, depois do mieloma múltiplo em adultos. Os locais frequentes das metástases, em caso de progressão da doença são os pulmões e os ossos. As metástases extrapulmonares são raras. O desenvolvimento de novos esquemas de quimioterapia melhorou a expectativa de vida dos pacientes com osteossarcoma, porém, alterou também os padrões usuais de metástases, resultando em localizações metastáticas incomuns.

Male adult with an osteosarcoma in proximal tibia, treated with limb salvage with endoprosthesis and chemotherapy. He developed an unusual metastatic pattern compromising liver, bone, and inguinal lymph nodes, without local recurrence in the tibia nor pulmonary metastases. Osteosarcoma (OS) is the second most frequent primary bone tumor after multiple myeloma in adults. Frequent sites of metastases in case of disease progression are the lungs and bone. Extrapulmonary metastases are rare. The development of new schemes of chemotherapy have improved life expectancy in osteosarcoma patients but also have altered the usual patterns of metastases, resulting in unusual metastatic locations.

Trabalho desenvolvido no Hospital Universitario San Ignacio -

Bogotá - Colômbia.

recebido

15 de Dezembro de 2020

aceito

15 de Janeiro de 2021
DOI https://doi.org/

$10.1055 / \mathrm{s}-0041-1731360$.

ISSN 0102-3616. (c) 2021. Sociedade Brasileira de Ortopedia e Traumatologia. All rights reserved.

This is an open access article published by Thieme under the terms of the Creative Commons Attribution-NonDerivative-NonCommercial-License, permitting copying and reproduction so long as the original work is given appropriate credit. Contents may not be used for commercial purposes, or adapted, remixed, transformed or built upon. (https://creativecommons.org/ licenses/by-nc-nd/4.0/)

Thieme Revinter Publicações Ltda., Rua do Matoso 170, Rio de Janeiro, RJ, CEP 20270-135, Brazil 


\section{Introdução}

Os avanços no desenvolvimento de novos esquemas de quimioterapia e radioterapia, assim como os avanços nas cirurgias ortopédicas oncológicas, melhorou o prognóstico dos pacientes com osteossarcoma (OS), aumentando a sobrevida de $15 \%$ para mais de $60 \% .^{1,2}$ No entanto, aproximadamente $40 \%$ dos pacientes apresentam recidiva e progressão da doença com metástases frequentes para os pulmões e ossos. ${ }^{2}$ Outros locais de comprometimento secundário, como os órgãos abdominais, linfonodos ou retroperitônio são raros. Apesar dos avanços nas opções de tratamento, o prognóstico dos pacientes com metástases incomuns permanece sombrio, com altas taxas de mortalidade. $\mathrm{O}$ uso de novos esquemas de quimioterapia pode estar associado à indução de padrões atípicos de disseminação e progressão da doença, possivelmente por favorecer a seleção de diferentes fenótipos das células tumorais. ${ }^{2}$ Apresentamos o caso de um homem adulto com envolvimento metastático incomum de osteossarcoma, causado por uma grande massa retroperitoneal, um conglomerado de linfonodos inguinais, com metástases hepáticas e ósseas sem recorrência local ou pulmonar.

\section{Relato de Caso}

Um homem de 46 anos de idade consultou-se por causa de dor no joelho esquerdo, com irradiação distal para a perna. Os estudos de raios-X e ressonância magnética exibiram uma lesão lítica da tíbia proximal, exigindo uma biópsia aberta confirmando o osteossarcoma (-Fig. 1A). As tomografias do tórax, abdômen e pelve foram negativas para lesões metastáticas. $\mathrm{O}$ tratamento neoadjuvante foi iniciado com 3 ciclos de doxorrubicina e cisplatina, 6 meses após a cirurgia de salvamento do membro com ressecção completa do tumor e reconstrução com endoprótese tibial proximal. A histopatologia confirmou um OS tibial proximal, com margens livres de tumor, e 30\% de tumor viável, indicando uma resposta de grau II A ao tratamento neoadjuvante.

Posteriormente, o paciente completou 3 ciclos de quimioterapia adjuvante com o esquema anterior, apresentando adequada tolerância ao tratamento e sem toxicidade. Após 1 ano do procedimento cirúrgico, apresentou episódios de linfedema do membro e dor. A ultrassonografia Doppler descartou trombose venosa profunda e a TC abdominal
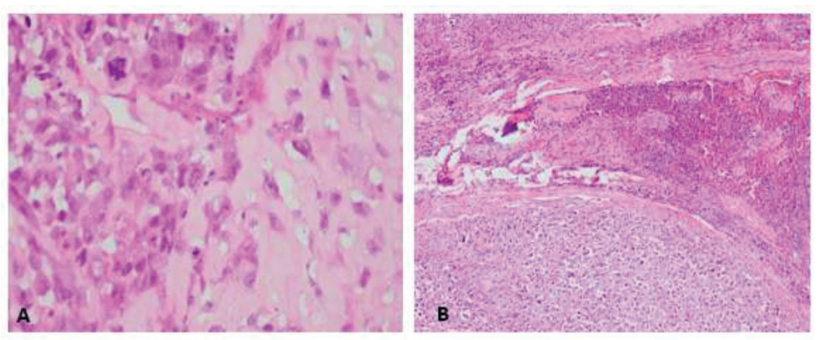

Fig. 1 (A) H/E 40x. Tumor maligno com produção de osteoide correspondendo a um osteossarcoma. (B) H/E 40x. Metástases de linfonodo de OS. Lâminas de células pleomórficas com necrose extensa, mitose e osteoide abundante.

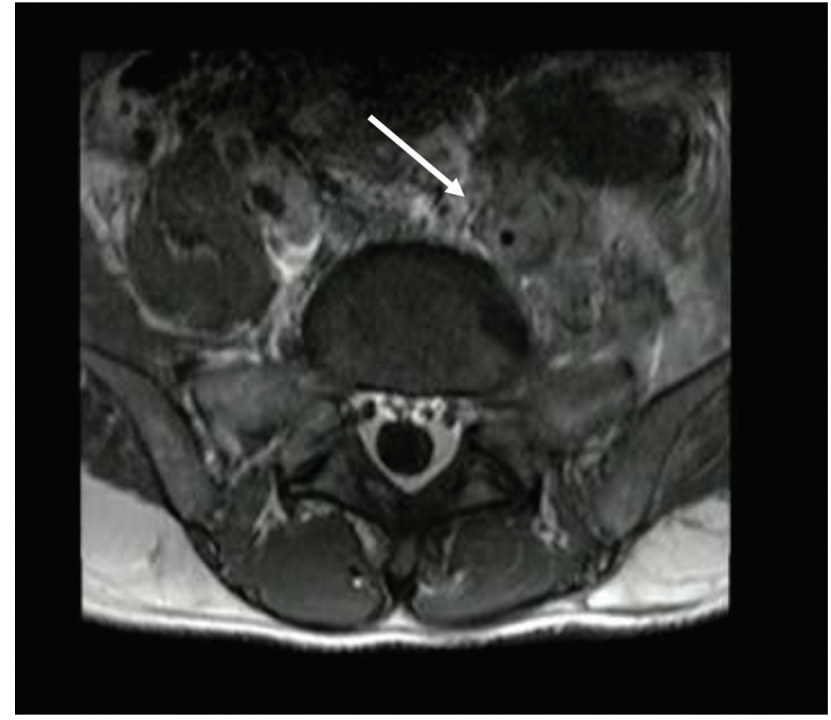

Fig. 2 Ressonância magnética da coluna lombossacra, evidenciando uma massa nos tecidos moles paravertebrais, infiltrando o corpo da vértebra L5 (seta).

revelou linfadenopatias inguinais e ilíacas. A TC do tórax revelou um nódulo pulmonar inespecífico menor que $1 \mathrm{~cm}$. Na época, o serviço de cirurgia torácica não considerava como uma lesão metastática. Posteriormente, foi realizada biópsia do linfonodo inguinal, a análise histopatológica confirmou tumor maligno e metástases de OS (-Fig. 1B).

Considerando que o paciente apresentava recidiva dos linfonodos e das partes moles inguinais, sem recidiva local no sítio inicial do tumor, optou-se pela ressecção da metástase. Durante a intervenção, foi evidenciada uma massa sólida de aproximadamente $10 \mathrm{~cm}$ de diâmetro na região inguinal esquerda, aderida à face lateral da bexiga, aos vasos ilíacos externos, ao cordão espermático e ao ligamento inguinal. Apresentava extenso comprometimento dos linfonodos inguinais, sendo realizada a dissecção linfonodo inguinoilíaca esquerda, obtendo-se uma ressecção R2 da massa (devido ao comprometimento das estruturas vasculares e da extensa fibrose das partes moles). O estudo histopatológico identificou múltiplas estruturas nodais conglomeradas de 5 a $6 \mathrm{~cm}$ de diâmetro, consideradas metástases com grande angioinvasão e extensão para os tecidos moles. Após essa intervenção, foi realizada uma quimioterapia paliativa com a administração dos fármacos gencitabina e docetaxel com 1 ciclo de tratamento.

Um mês depois, o paciente apresentou dor intensa no membro inferior esquerdo, além de monoplegia, insuficiência renal aguda e hematúria. Uma ressonância magnética da coluna lombossacra, revelou uma massa paravertebral anterolateral esquerda irregular, no segmento lombar inferior que infiltrava o músculo psoas e o córtex anterior do corpo vertebral L5 (-Fig. 2).

Além disso, a TC tóraco-abdominal contrastada identificou múltiplas lesões hipodensas compatíveis com metástases no parênquima hepático, ossos pélvicos e uma massa de aproximadamente $140 \times 78 \mathrm{~mm}$ no músculo psoas ilíaco esquerdo, se estendendo da L3 à região inguinal, circundando 


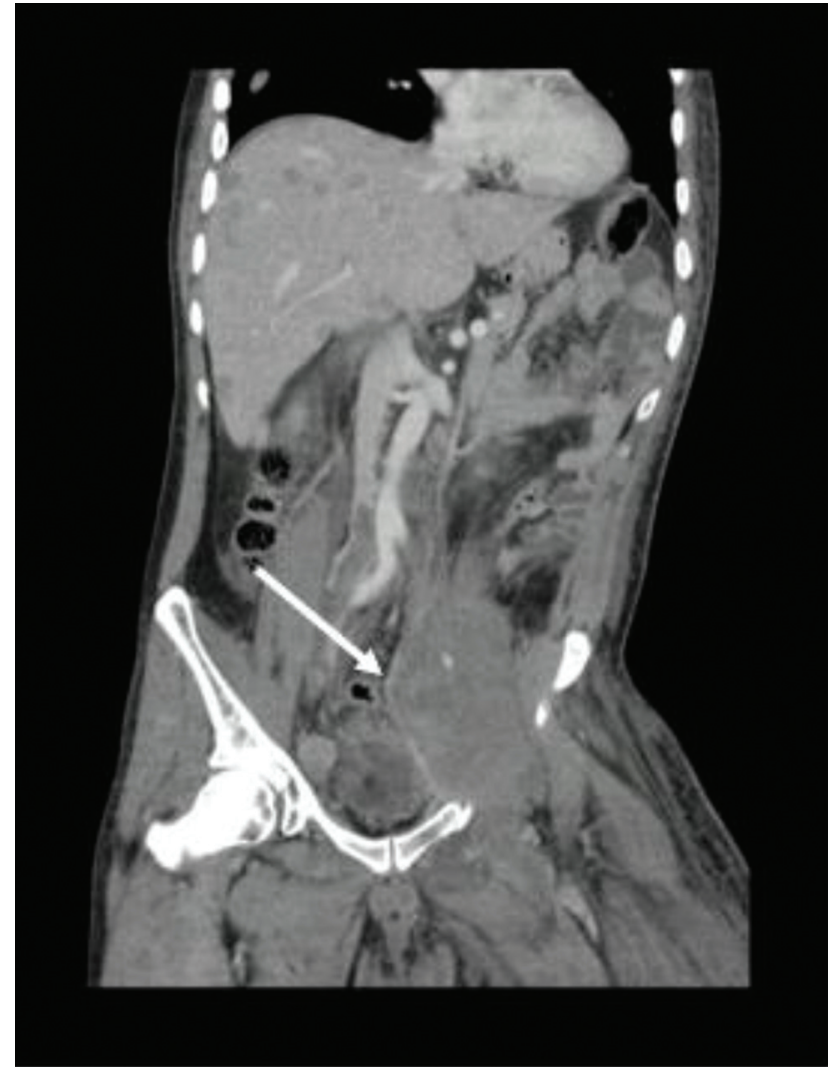

Fig. 3 TC tóraco-abdominal em corte coronal, com uma massa de tecido mole infiltrando o músculo psoas esquerdo com extensão para região inguinal (seta).

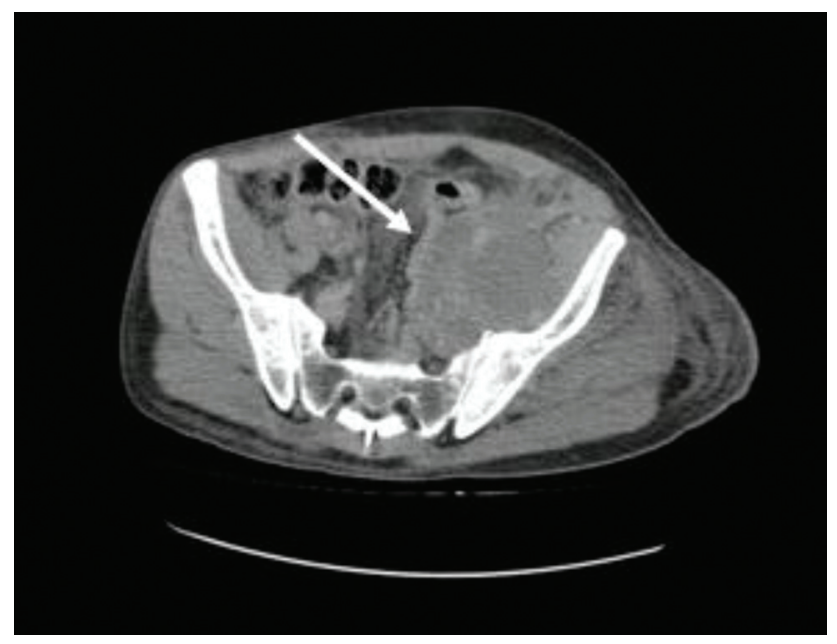

Fig. 4 TC abdominal em corte axial, com uma massa de tecido mole infiltrando o músculo psoas esquerdo (seta).

os vasos ilíacos interno e externo. Além disso, foram encontrados linfonodos para-aórticos, inter-aorto-cava e ilíaco externo direito (-Figs. 3 e $\mathbf{4}$ ).

Foi realizada biópsia dessa massa guiada por TAC, evidenciando envolvimento metastático devido a um osteossarcoma de alto grau (-Fig. 5).

O paciente persistiu com agravamento clínico, evoluiu com trombose venosa profunda no membro inferior

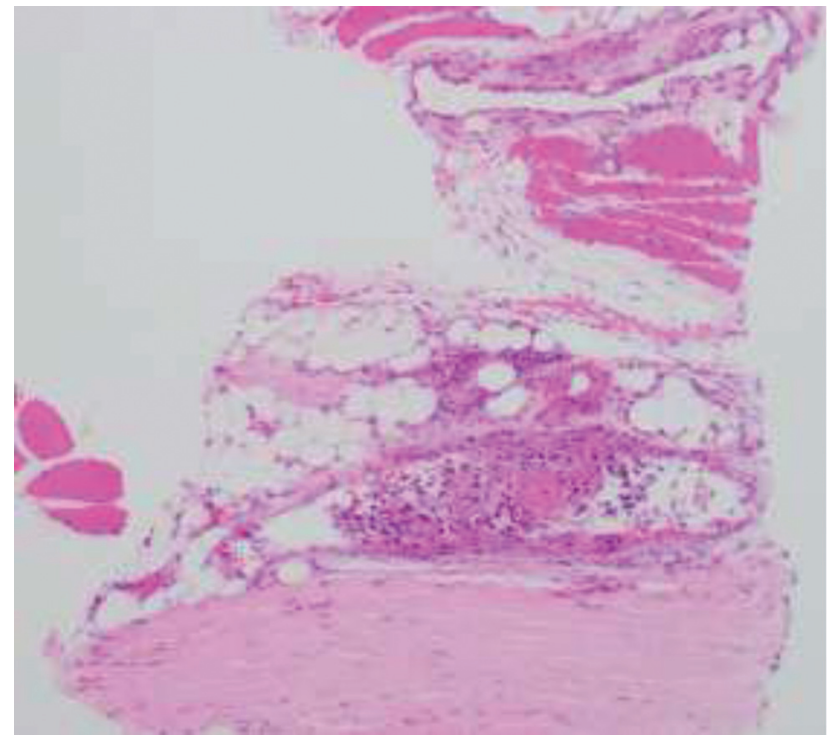

Fig. 5 H8/e 10x. Trombos neoplásicos com matriz osteoide entre células malignas compatíveis com OS metastático.

esquerdo e tromboembolismo pulmonar agudo, hematúria persistente e desidratação, falecendo dois anos depois do diagnóstico inicial de OS.

\section{Discussão}

A ocorrência de metástases faz parte do curso natural do osteossarcoma (OS), sendo a metástase pulmonar a mais frequente. ${ }^{1,3-7}$ Usando a quimioterapia como parte do tratamento integral, em relação ao que foi informado em 1975 por Jeffree et $\mathrm{al}^{8}{ }^{8}$ houve uma mudança nos padrões usuais da metástase. Embora isso possa ser o resultado de uma melhor identificação e também do relato de novos casos de OS, a melhora na sobrevida dos pacientes com OS revelou novos padrões de metástases extrapulmonares, particularmente no peritônio e linfonodos. ${ }^{1-3,6,7,9}$ A literatura não é clara a respeito da epidemiologia das metástases linfáticas em OS, a maioria das informações disponíveis vem de relatos de casos e séries de casos, com uma incidência entre $4 \%$ e $11 \%{ }^{1,6,7,9,10} \mathrm{~A}$ presença de micrometástases que podem levar à disseminação de OS também foi descrita, o que poderia impactar nas taxas de sobrevida. ${ }^{4}$

Um dos aspectos mais importantes que afetam a sobrevida dos pacientes com OS, é o desenvolvimento de metástases. ${ }^{1,8-10}$ Parece que a presença de certas metástases poderia estar associada a variantes mais agressivas do OS. ${ }^{1,6-10}$ Presume-se que essa mudança no padrão usual da metástase extrapulmonar, seja o resultado do uso de quimioterapias mais eficientes que visam certas células tumorais, deixando espaço para variantes mais agressivas com maior potencial metastático. ${ }^{2-5,9,10}$ Isso poderia explicar o resultado de linfonodo e metástases abdominais (especialmente as retroperitoneais) que estão associadas à recidivas de difícil controle e alta mortalidade no momento do diagnóstico. ${ }^{2,3,9,10}$

Este caso descreve um tipo de tumor ósseo agressivo e difícil de tratar, apresentando uma baixa taxa de resposta à quimioterapia, com recorrência distante, eventualmente, com desfecho fatal. Embora a presença de metástases em 
linfonodos seja incomum, a ocorrência de metástases extrapulmonares está aumentando, portanto, é essencial entender o escopo de um tumor que a ciência pode não ter totalmente compreendido.

\section{Suporte Financeiro}

Não houve suporte financeiro de fontes públicas, comerciais, ou sem fins lucrativos.

\section{Conflito de Interesses}

Os autores declaram não haver conflito de interesses.

\section{Referências}

1 Lin JT, Yen CC, Wang WS, et al. Case report: Unusual peritoneal spreading by metastatic osteosarcoma of the tibia. Br J Radiol 2003;76(905):337-338

2 Bacci G, Ruggieri P, Picci P, et al. Changing pattern of relapse in osteosarcoma of the extremities treated with adjuvant and neoadjuvant chemotherapy. J Chemother 1995;7(03): 230-239
3 Oñoro G, Hernández C, Sirvent S, et al. Unusual sites of extrapulmonary metastases of osteosarcoma after several lines of treatment. Pediatr Hematol Oncol 2011;28(07):604-608

4 Berhe S, Danzer E, Meyers P, Behr G, LaQuaglia MP, Price AP. Unusual abdominal metastases in osteosarcoma. J Pediatr Surg Case Rep 2018;28:13-16

5 Giuliano AE, Feig S, Eilber FR. Changing metastatic patterns of osteosarcoma. Cancer 1984;54(10):2160-2164

6 Hattori H, Yamamoto K. Lymph node metastasis of osteosarcoma. J Clin Oncol 2012;30(33):e345-e349

7 Vasiliev NV. Lymph node metastasis of osteosarcomas. [Limfogennoe metastazirovanie sarkom kosti.] Arkh Patol 2016;78(04): 58-63

8 Jeffree GM, Price CH, Sissons HA. The metastatic patterns of osteosarcoma. Br J Cancer 1975;32(01):87-107

9 Yanagawa T, Saito K, Takagishi K. Risk factors for lymphatic metastasis of malignant bone and soft-tissue tumors: a retrospective cohort study of 242 patients. Medicine (Baltimore) 2014; 93(27):e225

10 Lev-Chelouche D, Nakache R, Soffer D, Merimsky O, Klausner MJ, Gutman M. Metastases to the retroperitoneum in patients with extremity soft tissue sarcoma: an unusual metastatic pattern. Cancer 2000;88(02):364-368 